\title{
Immune Complex Processing in Patients with Systemic Lupus Erythematosus
}

\author{
In Vivo Imaging and Clearance Studies
}

Kevin A. Davies, A. Michael Peters, * Huw L. C. Beynon, and Mark J. Walport

Rheumatology Unit and *Department of Diagnostic Radiology, Hammersmith Hospital, London W12 OHS, United Kingdom

\begin{abstract}
Abnormal processing of immune complexes (IC) may be important in the pathogenesis of systemic lupus erythematosus (SLE). The clearance of large soluble IC (comprising hepatitis B surface antigen (HBsAg)/anti-HBsAg) radiolabeled with ${ }^{123}$ I was examined in 12 normal subjects and 10 patients with SLE. IC localization was analyzed by static and dynamic gamma-scintigraphy. Initial IC clearance from blood was more rapid in patients (median $t_{1 / 2}=2.15 \mathrm{~min}$ ) than normals (median $t_{1 / 2}=5.15 \mathrm{~min}$ ) due to more rapid uptake in the liver. However, in the SLE group, up to $12 \%$ of complexes were released from the liver after 30-50 min. Splenic uptake of immune complexes was reduced in the patients and there was reduced ability to retain IC in this organ. Plasma complement levels and erythrocyte complement receptor type 1 numbers were reduced in the patients, resulting in defective opsonization of $\mathrm{IC}$ and reduced red cell binding in vivo. These observations support the hypothesis that IC handling is abnormal in SLE. (J. Clin. Invest. 1992.90:2075-2083.) Key words: complement - complement receptor type 1 - mononuclear phagocytic system - autoimmune disease $\bullet$ antigen processing
\end{abstract}

\section{Introduction}

There are several ways in which abnormal processing of immune complexes (IC) ${ }^{1}$ may play a role in the pathogenesis of systemic lupus erythematosus (SLE). Immune complexes may escape clearance and catabolism by the mononuclear phagocytic system (MPS) because of abnormal transport or presentation mechanisms (1). Furthermore, there may be defects in MPS function in patients with SLE, and hypotheses to explain these have included "saturation" by immune complexes (2) and intrinsic abnormalities of phagocytic cell function (3).

Address reprint requests to Dr. Kevin A. Davies, Rheumatology Unit, Department of Medicine, Hammersmith Hospital, London W12 0HS, United Kingdom.

Received for publication 14 October 1991 and in revised form 22 April 1992.

1. Abbreviations used in this paper: A-IgG, aggregated IgG; CR, complement receptor; $\mathrm{HBs} A g$, hepatitis $B$ surface antigen; IC, immune complex; MPS, mononuclear phagocytic system.

J. Clin. Invest.

(c) The American Society for Clinical Investigation, Inc. $0021-9738 / 92 / 11 / 2075 / 09 \$ 2.00$

Volume 90, November 1992, 2075-2083
Studies in vivo in primates have delineated the mechanism of clearance from the circulation of soluble immune complexes. In baboons, IgG-containing immune complexes fixed complement, bound to complement receptor type 1 (CR1) on erythrocytes and were transported to the fixed mononuclear phagocytic system where they were cleared from the circulation (4). Several investigators have used soluble immune complexes or aggregated IgG to study the clearance pattern of immune complexes from the circulation of humans (5-9). Abnormally fast clearance of immune complexes in patients with SLE was observed and correlated with hypocomplementemia (7). These studies were performed using ${ }^{125}$ I-labeled immune complexes and it was not possible to ascertain the site of rapid clearance of immune complexes. Imaging studies performed using heat-aggregated IgG showed accelerated uptake in the liver (10).

We describe here the results of experiments using ${ }^{123}$ I-hepatitis B surface antigen-containing immune complexes to track the fate of immune complexes in normal humans and patients with SLE. Several abnormalities of immune complex kinetics were identified in patients with SLE, hypocomplementemia, and low CR1 numbers. These were accelerated clearance of immune complexes in the liver, impaired retention of complexes within the liver with release of complexes back to the circulation, and impaired immune complex clearance by the spleen.

\section{Methods}

\section{Subjects}

26 subjects were studied, 18 female and 8 males. 12 normal volunteers were recruited from the laboratory staff, aged from 23 to $59 \mathrm{yr}, 6 \mathrm{female}$ and 6 male. Four additional normal subjects (three female, one male) received radiolabeled antigen alone. The patients were 10 subjects with SLE, aged from 21 to $56 \mathrm{yr}, 9$ females and 1 male, all of whom fulfilled the revised ARA criteria for this disease. At the time of the study, 8 of the 10 patients had clinically active disease involving more than one organ system, with an erythrocyte sedimentation rate $>40 \mathrm{~mm}$ in the first hour in all cases, and a $\mathrm{C} 4<50 \%$ normal human serum pool, elevated DNA binding ( $>30 \%$ by Farr assay), or both. Two patients were studied on two occasions. Fully informed consent was obtained from all the participants for the study, which was approved by the Hammersmith Hospital Ethics committee and the Administration of Radioactive Substances Advisory Committee (ARSAC).

All subjects received $120 \mathrm{mg}$ twice daily of oral potassium iodide for $36 \mathrm{~h}$ before each study and a further $48 \mathrm{~h}$ after injection to block thyroid uptake of ${ }^{123} \mathrm{I}$.

Hepatitis B surface antigen (HBsAg)

This was a gift from Dr. J. A. Schifferli (Hôpital Cantonale, Geneva, Switzerland). The antigen was in the form of a large polymeric protein (molecular mass around 3,000 kD) and was pyrogen free. It has been previously characterized both in vitro and in vivo (11). $30 \mu \mathrm{g}$ antigen was used for the preparation of each batch of IC. 


\section{Anti-HBsAg antibody}

Polyclonal antiserum to HBsAg was also a gift from Dr. Schifferli (Croix-Rouge, Bern, Switzerland). One vial of sterile lyophilized immunoglobulin (>95\% IgG1) was dissolved in $10 \mathrm{ml}$ sterile water (Antigen, UK), to produce a final concentration of $50 \mathrm{U} / \mathrm{ml}$, immediately before IC preparation.

\section{Radiolabeling of HBsAg}

The antigen was labeled with ${ }^{123}$ I (Medgenex, Brussels, Belgium), using $N$-bromosuccinamide (12), to a high specific activity $(25-30 \mu \mathrm{Ci} / \mu \mathrm{g})$. $30 \mu \mathrm{g}$ of antigen was labeled immediately before each study; free and bound iodine were separated on a sterile G25 column preblocked with sterile human albumin. The ${ }^{123} \mathrm{I}$ was $>97 \%$ protein bound in the final preparation in all cases.

\section{IC preparation}

$\mathrm{HBsAg} /$ anti-HBsAg IC were prepared as follows: $30 \mu \mathrm{g}$ of radiolabeled $\mathrm{HBsAg}$ was incubated with $10 \mathrm{ml}$ of antiserum for $60 \mathrm{~min}$ at $37^{\circ} \mathrm{C}$. This corresponds to a fivefold antibody excess. Two 5-ml samples were then drawn into syringes, and the total radioactivity in each dose measured using a radioisotope calibrator (ARC 120, Capintec; Amersham, Amersham, UK). An IC mixture containing $15 \mu \mathrm{g}$ of antigen was used for each subject, with an activity of between 300 and $500 \mu \mathrm{Ci}$. For each batch of labeled IC prepared, one patient and one normal control were studied in parallel.

\section{Injection and imaging protocol}

An intravenous cannula was inserted into the subject's left antecubital fossa for injection of labeled IC and into a similar line in the right arm for blood sampling. $5 \mathrm{ml}$ of IC was injected as a rapid bolus at time 0 , with the patient positioned over a gamma-camera (IGE 400T on-line to an MDS $\mathrm{A}^{2}$ computer). Dynamic imaging was performed (serial $20 \mathrm{~s}$ frames) for $50 \mathrm{~min}$, followed by 5 -min anterior and posterior static imaging at 1, 4, and $24 \mathrm{~h}$. Four subjects underwent dynamic scanning for $2 \mathrm{~h}$, and whole-body scanning was also performed in two cases, using a Starcam (IGE) gamma camera.

\section{Blood samples}

Preinjection serum and erythrocytes were obtained from all subjects for the estimation of serum complement levels and red cell CR 1 numbers. Postinjection, 6-ml venous blood samples were taken into EDTA pH 7.2 at $2,5,10,15,20,25$, and $30 \mathrm{~min}$, and then at 10-min intervals up to $1-2 \mathrm{~h}$. Further samples were then obtained at the time of rescanning. The following assays were performed on each blood sample:

Measurement of whole blood ${ }^{123} \mathrm{I}$. A 1-ml aliquot from each EDTA sample was counted for ${ }^{123}$ I activity using an automated gamma counter (LKB Wallac, Turku, Finland).

Identification of protein-bound ${ }^{123}$ I. A 1 -ml aliquot of each EDTA sample was lysed by mixing with an equal volume of water. Proteinbound activity was measured by treatment of 250-2000- $\mu$ l aliquots of plasma or lysed whole blood with trichloroacetic acid (BDH Chemicals Ltd., Dagenham, Essex, England) at a 10\% vol/vol final concentration, and counting for ${ }^{123} I$ in the washed precipitate.

Measurement of erythrocyte-bound ${ }^{123} I .2 \mathrm{ml}$ of each freshly drawn EDTA sample was immediately diluted 1:4 in ice-cold PBS pH 7.4/1\% BSA, and red blood cells were rapidly separated from plasma by centrifugation at $1,500 \mathrm{~g}$. Cells were subsequently washed three times in the same buffer. There was no significant release of erythrocyte-bound ICs during the washing procedure. Washed cells were counted for ${ }^{123}$ I activity, with correction for isotopic decay in the later samples.

Characterization of ICs. (a) Coprecipitation of ${ }^{123} \mathrm{I}-\mathrm{HBsAg}$ using Staphylococcal protein A was as follows: precipitation of ${ }^{123} \mathrm{I}-\mathrm{HBsAg}-$ containing ICs was performed by addition of $50 \mu \mathrm{l}$ of a suspension of Staphylococcal protein A-coated beads (Calbiochem, Cambridge Bioscience, Cambridge, UK) to $100 \mu$ l plasma samples, followed by incubation for $10 \mathrm{~min}$ at room temperature, and two washes in PBS/1\% BSA performed by centrifugation at $1,000 \mathrm{~g}$, with resuspension of the pellet each time. The ${ }^{123} \mathrm{I}$ activity in pellet and supernate was then measured.

(b) Sucrose density gradient centrifugation was as follows: to ascertain complex size, $100-\mu l$ aliquots of fresh plasma were layered onto a $10-50 \%$ sucrose gradient (13), and ${ }^{123}$ I activity was measured in 16 fractions of $300 \mu \mathrm{l}$ after centrifugation for $4 \mathrm{~h}$ at $30,000 \mathrm{~g}$. Radiolabeled IgM, IgG, and BSA were used as size markers.

\section{Complement assays}

Plasma $\mathrm{C} 3$ and $\mathrm{C} 4$ levels were measured using single radial immunodiffusion in $1.2 \%$ complement fixation diluent-agarose gels containing antibody (polyclonal goat anti-human C3, or sheep anti-human C4 [Serotec Ltd., Oxford, UK]). CH50 was measured using a plate hemolytic assay (14).

\section{Assay for enumeration of erythrocyte CRI}

Mean numbers of antigen sites on erythrocytes were measured using a radioligand-binding assay, as previously described (15). Monoclonal antibody to CR1 was E11 (16) (donated by Dr. Nancy Hogg, Imperial Cancer Research Fund, London, England). Radiolabeling was performed with ${ }^{125}$ I (Amersham) using Iodogen (17), to a specific activity of $1-2 \mu \mathrm{Ci} / \mu \mathrm{g}$.

\section{Image analysis}

Quantification of uptake in the liver and spleen was performed from radioactivity count rates in specific "regions of interest" drawn respectively around the liver and spleen on anterior and posterior images. Hepatic and splenic uptake was quantified by comparing the injected counts with the geometric mean of anterior and posterior counts in the specific regions of interest. Corrections were made for physical decay of the radionuclide and photon attenuation as previously described (18).

\section{Statistical methods}

Elimination half-times, time of $90 \%$ hepatic uptake, splenic uptake, and other variables were compared between the patients and control group using the Mann-Whitney $U$ test. Correlations between $\mathrm{C} 4$ and C3 levels and IC clearance rate, red cell CR 1 numbers and IC binding, and CR 1 numbers and hepatic clearance were analyzed using the nonparametric Spearman rank correlation test.

\section{Results}

\section{Studies with HBsAg alone}

Control experiments were performed to characterize the clearance pattern of the HBsAg when injected alone. $15 \mu \mathrm{g}$ of ${ }^{123} \mathrm{I}-\mathrm{la}-$ beled antigen was injected into two immune and two nonimmune normal volunteers. Localization of antigen to the liver and spleen occurred in all cases, maximum uptake in the liver occurring after 22 and $24 \mathrm{~min}$, and 28 and $35 \mathrm{~min}$ in the immune and nonimmune subjects, respectively. Splenic uptake of radioactivity at $1 \mathrm{~h}$ was between 4 and $7.5 \%$ of the injected dose in the four subjects studied, and there was no difference between immune and nonimmune individuals. However, more rapid splenic localization occurred in the immune (mean $t_{1 / 2}=9 \mathrm{~min}$ ) than in the nonimmune subjects ( mean $t_{1 / 2}=21$ min). Less than $2 \%$ of circulating activity was measured on erythrocytes in the nonimmune subjects whereas 12 and $14 \%$ binding was observed in the immune controls. Maximum binding in the immune subjects occurred between 5 and $10 \mathrm{~min}$, much less rapidly than in those patients injected with preformed IC ( see below).

\section{IC imaging studies}

Initial IC clearance and localization. In SLE patients and controls there was uptake of IC in the liver and spleen, with rapid clearance from the blood (Fig. $1 a$ ). Scanning over the lungs, 

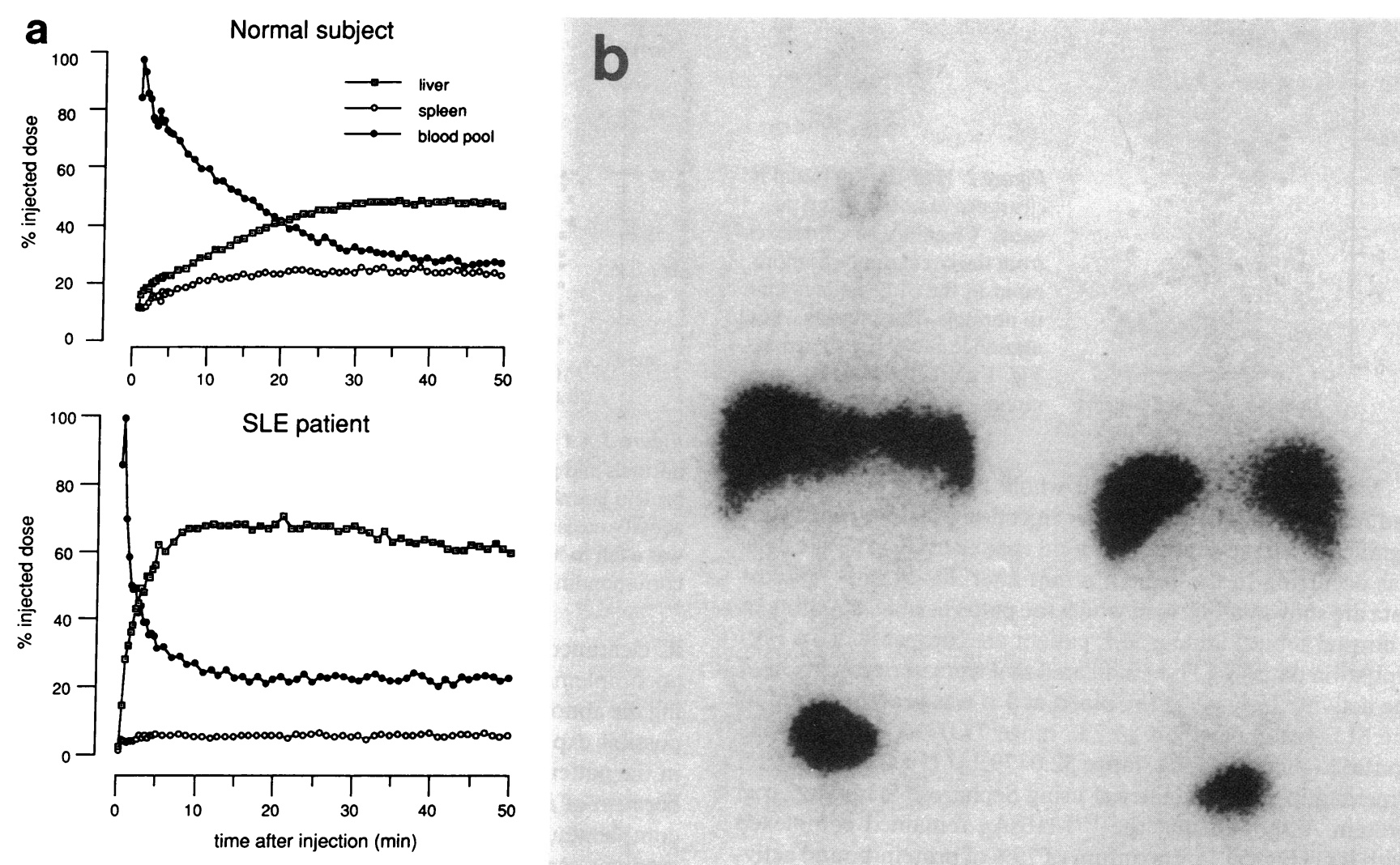

Figure 1. (a) IC clearance kinetics in a typical normal control subject and a patient with SLE. IC were rapidly cleared from the blood and taken up by the liver and spleen. Complex clearance from the circulation was more rapid in the SLE patient, and there was more rapid IC uptake in the liver. $(b)$ Whole-body scan performed at $2 \mathrm{~h}$ in a normal subject (anterior, left; posterior, right). Tracer uptake is seen in the liver and spleen and free iodine produced by IC catabolism is visible in the bladder.

kidneys, and other organs revealed no specific uptake above blood pool level in either group (Fig. $1 b$ ). The initial rate of IC clearance from blood was significantly faster in the SLE group ( median $t_{1 / 2}=2.15 \mathrm{~min}$ [range 1.3-6.6 $\mathrm{min}$ ]) than in the normal controls (median $t_{1 / 2}=5.15$ min [range 3.6-14]) $(U$ $=12.5, P<0.002)$ (Fig. 2). As is shown in Fig. $1 a$, the rapid initial removal of complexes from the blood in the patients with SLE corresponded with the time course of localization of immune complexes in the liver. The median time at which $90 \%$ of maximum hepatic uptake was achieved in the patients with SLE was $9.0 \mathrm{~min}$ ( range 4.3-18 min) compared with $16.0 \mathrm{~min}$ (13-23 $\mathrm{min})$ in the control subjects $(U=8.0, P<0.002)$. At 10 min, between 27.3 and $67.5 \%$ (median $40.7 \%$ ) of injected ICs were detectable in the liver in the normal subjects compared with 43.0 to $79.6 \%$ of injected IC (median $56.3 \%$ ) in the patient group ( $U=27, P<0.05)$. The immune status of the subject to HBsAg ( measured by a standard ELISA in the Virology Department, Royal Postgraduate Medical School, Hammersmith Hospital) had no bearing on clearance rate, hepatic uptake, or subsequent handling in the studies performed with immune complexes.

IC catabolism and release. Although there was rapid initial hepatic localization of complexes in both normals and patients, in both groups there was a fall in hepatic activity observed between $30 \mathrm{~min}$ and $2 \mathrm{~h}$. This was more noticeable in the patient group, as demonstrated by comparison of the ratio of hepatic counts measured at 40 and $60 \mathrm{~min}$ in the two groups, median ratio 1.24 (range $0.88-1.44$ ) in the studies performed in patients with SLE compared with $0.75(0.48-0.95)$ in the controls $(U=2, P<0.02)$ (Fig. $3 B)$. 


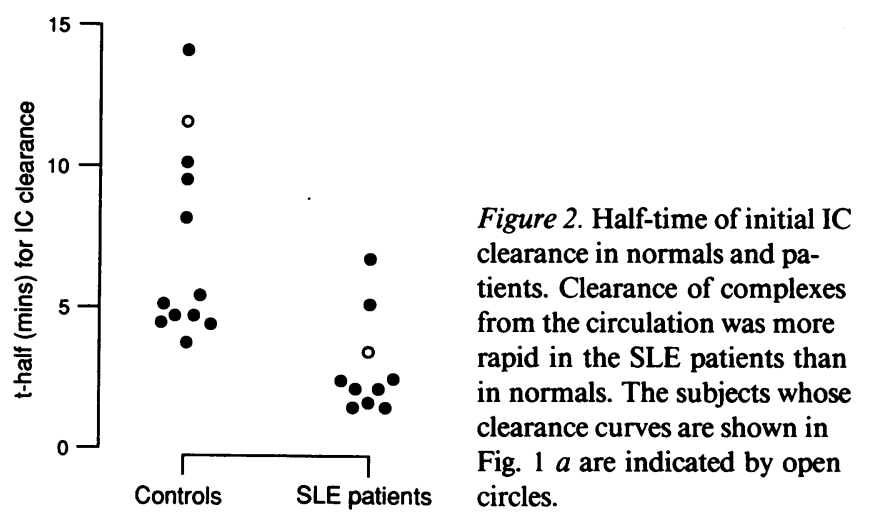

Measurement of sequential whole blood, protein-bound, and red cell-bound activity after injection of IC indicated that significant release of protein-bound radioactivity from the liver was occurring in the patient group after 30-40 min. Typical data are shown in Fig. 4, in which the patterns of IC handling in a normal subject and an SLE patient are compared. TCA precipitation data (Fig. $3 \mathrm{~A}$ ) indicated that a greater proportion of the activity detected in the blood at $1 \mathrm{~h}$ was protein bound in the SLE group (median $86.7 \%$, range 77.0-96.7) than in the controls (median 69.7\%, range 52.0-79.1) $(U=2.0, P<0.02$ ). Precipitation of this material using Sepharose-Staphylococcal protein A showed that the ${ }^{123} \mathrm{I}-\mathrm{HBsAg}$ remained complexed with IgG (Fig. 5). A maximum of $79 \%$ of protein-bound activity could be precipitated with Sepharose-Staphylococcal protein $\mathrm{A}$ at $100 \mathrm{~min}$ in the patients studied. The size of this material was assessed by sucrose density gradient centrifugation, which showed it to be composed primarily of material of between 35 and $50 \mathrm{~S}$, intermediate between antigen and the injected ICs (Fig. 6, $a$ and $c$ ).

Splenic IC uptake. There was significantly reduced splenic uptake of immune complexes during the first hour among the patients (median, 9.03\% of injected ICs; range, 4.05-23.7\%) compared with the normal controls (median, 23.9\%; range, $17.9-30.7 \%)(U=4, P<0.02)$ (Fig. $7 a)$. The ability of the spleen to retain ICs after initial uptake into the organ was also abnormal among the SLE patients. The activity remaining in the spleen at $24 \mathrm{~h}$ after injection was expressed as a percentage of the maximum organ uptake measured during the first hour after injection of the ICs. Among the SLE patients median uptake was $39 \%$ maximum (range: $24-52 \%$ ) compared with normal subjects (median, $65.5 \%$; range, 58-73\%) $(U=0, P$ $<0.002$ ) (Fig. $7 \mathrm{~b}$ ). It was not possible to track the localization of IC for $>24 \mathrm{~h}$ because of the short half-life of ${ }^{123} \mathrm{I}$.

\section{Factors influencing clearance pattern in normals and patients}

The main differences between the control subjects and patients with SLE were as follows: $(a)$ initial IC clearance was more rapid in patients than in normals, as complexes localized in the liver, (b) IC release from the liver occurred subsequently in patients; and $(c)$ there was significantly reduced splenic complex uptake in the patient group. The possible factors contributing to these differences were explored:

Hypocomplementemia and IC size. Among the 10 subjects with SLE there was a close correlation between the level of C4 in the plasma and the $t_{1 / 2}$ of IC clearance, $r_{\mathrm{Sp}}=0.997$ (Fig. 8). There was also a correlation between plasma $\mathrm{C} 3$ and the $t_{1 / 2}$ of
A

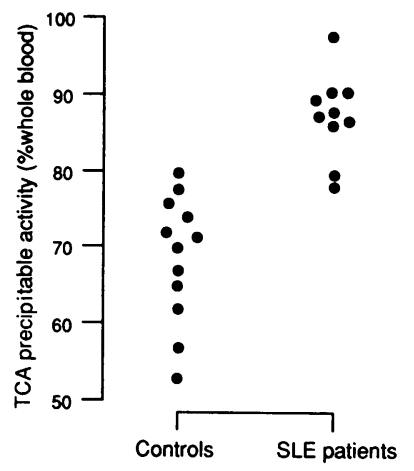

B

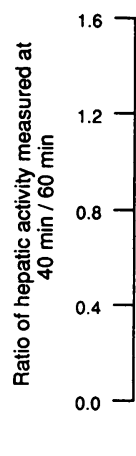

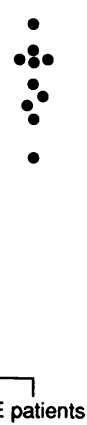

Figure 3. (A) TCA-precipitable activity measured in blood at $1 \mathrm{~h}$ in normals and patients. A greater proportion of radioactivity was still protein bound at $1 \mathrm{~h}$ in patients than in normals. $(B)$ Ratio of hepatic activity measured at 40 and $60 \mathrm{~min}$ in normals and patients. There was a fall in hepatic activity between 40 and $60 \mathrm{~min}$ in the SLE group, corresponding to release of ICs.

IC clearance, $r_{\mathrm{Sp}}=0.811$. These observations suggest that hypocomplementemia might play an important role in determining the abnormal IC kinetics among the patients with SLE. One possible explanation for this link is that the ICs remained larger in the patients after injection than among the normal controls because of inefficient solubilization in the presence of hypocomplementemia. Assessment of IC size by sucrose density gradient centrifugation performed on samples of plasma obtained immediately after complex injection was in support of this hypothesis. Typical gradient data are shown in Fig. 6 . A shift in peak complex size was seen in the 3-and 5-min samples drawn from a normal subject, which was not observed in the samples from an SLE patient.

Erythrocyte CRI number and IC binding. The median erythrocyte CR1 number measured in the normal control group was 950 (range 467-1,218). The median value for the SLE patients was significantly lower, 482 (range 78-969) ( $U$ $=19, P<0.02$ ). Among all subjects there was a very close linear correlation between the maximum binding in vivo of IC to erythrocytes and the CR1 number $\left(r_{\mathrm{Sp}}=0.96\right)$. CR1 numbers on erythrocytes were also correlated with the rate of clearance of ICs by the liver $\left(r_{\mathrm{Sp}}=0.62, P=0.002\right)$.

\section{Patients studied on two occasions}

Two patients with SLE were studied twice, at intervals of 8 and 9 mo, respectively. Both had been treated with corticosteroids and azathioprine during the interim period, with clinical and serologic improvement manifest by a rise in $\mathrm{C} 4$ and a fall in DNA binding ( see Table I). CR 1 numbers on erythrocytes rose by only 14 and 12 molecules per cell, respectively. The measured $t_{1 / 2}$, time for $90 \%$ liver uptake, and percentage hepatic and splenic uptake data are shown in Table I. In both subjects a rise in $\mathrm{C} 4$ correlated with an increased clearance time and reduced hepatic uptake, with correspondingly greater splenic localization of complexes. IC release into the circulation between 30 and 60 min occurred but was reduced in the second set of studies.

\section{Discussion}

The use of ${ }^{123}$ I-labeled soluble immune complexes offers the opportunity for the analysis of the physiological mechanisms 

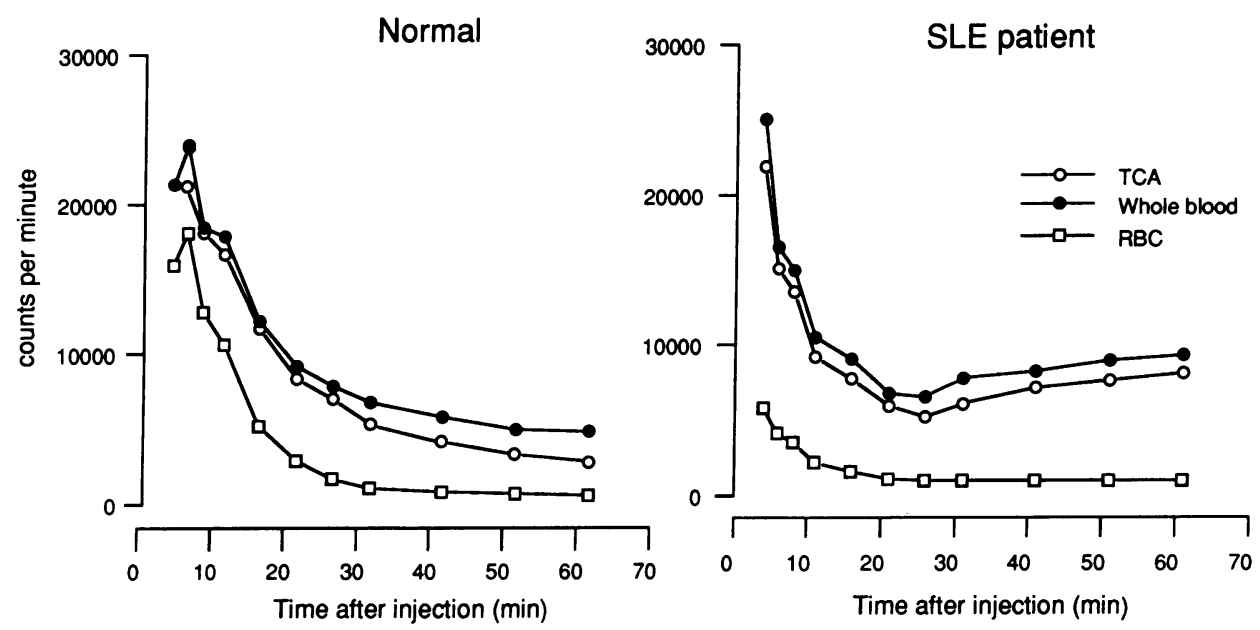

\begin{abstract}
Figure 4. Radioactivity measured sequentially in blood after IC injection, whole blood, TCA-precipitable, and RBC-bound activity, comparison between a typical normal and a patient. There was more rapid clearance of IC in patients, with reduced binding to erythrocyte CR1.
\end{abstract}

of immune complex clearance from the circulation in humans and how these may be perturbed in disease. We found three main differences between the clearance pattern of immune complexes in normal subjects and patients with SLE. Clearance of immune complexes by the liver was faster in patients with SLE than in controls (the opposite result to that previously observed for clearance of IgG-coated erythrocytes by the spleen [3]), and the increased clearance rate correlated with hypocomplementemia and reduced erythrocyte CR 1 numbers. The second difference was that uptake and internalization of immune complexes by the MPS of the liver was abnormal in patients with SLE; up to $12 \%$ of the injected $\mathrm{HBsAg}$, still com-
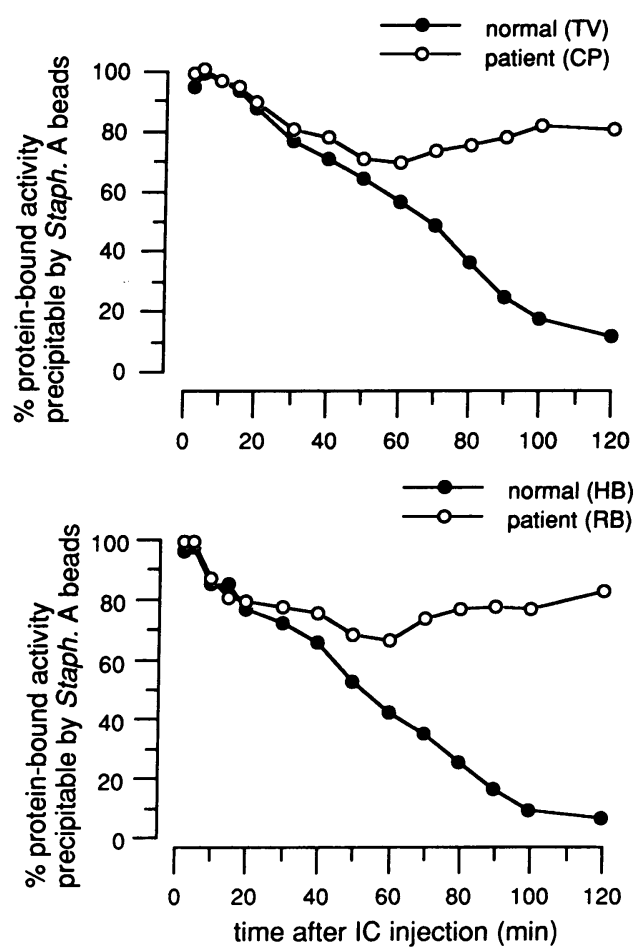

Figure 5. Precipitation of IC by Staphylococcus A beads in normals and patients. In the SLE patients between $40 \mathrm{~min}$ and $2 \mathrm{~h}$ there was an increase in the proportion of protein-bound activity in blood which was precipitable by Staphylococcus A. plexed with antibody, was released back into the circulation from the liver, a phenomenon not seen in normal control subjects. The third difference was that there was much reduced IC uptake in the spleen in the patients compared with controls. We performed preliminary experiments to study the clearance of labeled antigen alone in immune and nonimmune subjects and the results were similar to those obtained previously by Madi et al. (11). Antigen cleared in both liver and spleen but with kinetics much slower than those of IC. Maximum in vivo binding of nascent IC to erythrocyte CR 1 in immune subjects was $14 \%$, similar both to that measured by Madi et al. (11) and that observed in our previous study of in vivo IC formation and clearance in patients receiving radioimmunotherapy (19).

Three interrelated factors appeared to be important in determining the faster clearance and localization of immune complexes in the liver in patients compared with normal subjects. These were hypocomplementemia, large IC size, and reduced binding to erythrocyte CR1, each of which was associated with increased rate of uptake of immune complexes by the liver. A close correlation was observed between the level of the classical pathway component $\mathrm{C} 4$ and the initial rate of IC clearance. The results of previous work in vitro (20-22) and in vivo (7) implied that low levels of complement might have two main effects on complex processing. Firstly, IC size would be expected to be greater due to defective complex solubilization $(21,22)$. This was confirmed in the present study on six occasions using sucrose density gradient analysis. Secondly, defective coating of immune complexes with complement would reduce binding to $C R 1$ on erythrocytes. $C R 1$ numbers on the erythrocytes of patients with active SLE are significantly lower than in normal controls $(15,23-25)$. This was also the case in the present study, and low levels of erythrocyte CR1 correlated closely with reduced IC binding to erythrocytes.

The scanning results showed release of ${ }^{123}$ I counts from the liver during the first 60 min among the SLE patients, which was not seen in normal subjects. Two possible explanations for this observation are faster internalization and catabolism of complexes in the SLE patients followed by early release of free ${ }^{123} I$ or impaired cellular internalization of immune complexes with release of immune complexes back into the circulation. Several lines of evidence are in favor of the second hypothesis: $(a)$ the ${ }^{123}$ I counts were protein bound as judged by their coprecipitation with protein after trichloracetic acid; $(b)$ they were still in 

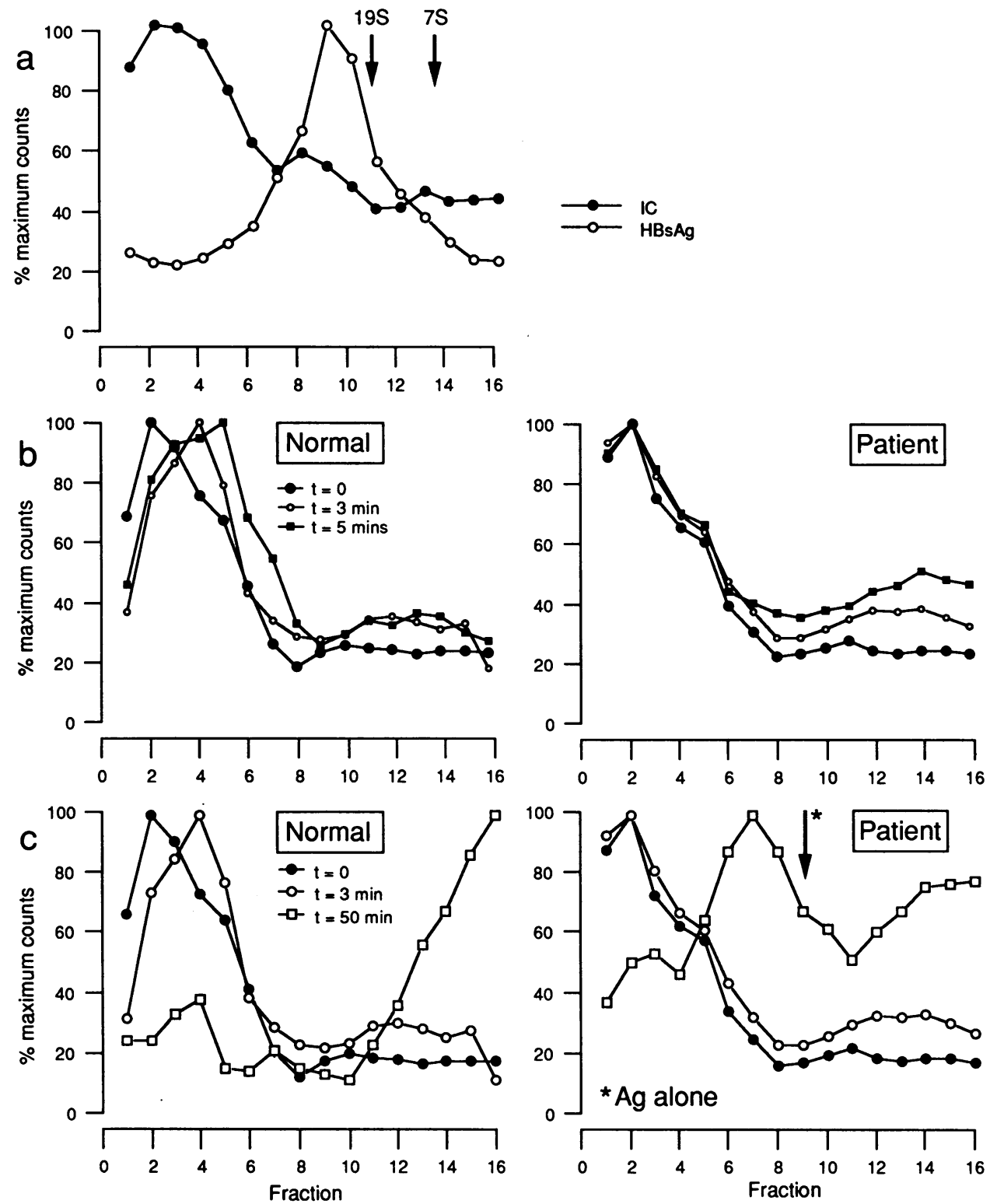

Figure 6. (a) Sucrose density gradient profiles generated by radiolabeled antigen alone and by IC preparation immediately before injection. The antigen is $\sim 30 \mathrm{~S}$ in size. (b) Sucrose density gradient analysis of plasma samples obtained from a patient and a normal subject at $\mathbf{t}$ $=0,3$, and 5 min. (c) Sucrose density gradient analysis of plasma samples obtained from a patient and a normal subject at $t=0,3$, and 50 $\mathrm{min}$. At $50 \mathrm{~min}$ material was present in the circulation intermediate in size between antigen and injected ICs.

the form of immune complexes because they bound to Staphylococcal protein $\mathrm{A}$, which only bound the ${ }^{123} \mathrm{I}-\mathrm{HBs} \mathrm{Ag}$ when complexed with antibody; and $(c)$ the size of the released material was $\sim 30 \mathrm{~S}$ when analyzed by sucrose density centrifugation. In contrast, there was evidence that uptake and processing of immune complexes in both liver and spleen, with consequent release of free ${ }^{123} \mathrm{I}$, was more efficient among the normal control subjects (Fig. 3 ).

There is a precedent for these results from experiments on clearance mechanisms of immune complexes in mice with SLE-like disease. The clearance of cross-linked mouse antiDNP oligomers was studied in NZB/W and control mice, both in vivo (26) and in isolated perfused livers (27). Immune complexes were cleared in vivo mainly in the liver, $76 \%$ of the injected label localized to the liver at $1 \mathrm{~h}$. Initial clearance from the circulation was more rapid in the $\mathrm{NZB} / \mathrm{W} \mathrm{F}_{1}$ lupus mice than in control mice (26), analogous to the observations reported in the present study. The early stages of IC uptake were examined by perfusing isolated murine livers via the portal vein with labeled immune complexes. There was initially enhanced hepatic uptake in the autoimmune mice compared with controls. However, the complexes in the NZB and NZB/ $W F_{1}$ lupus mice could be readily displaced by saturating doses of heat-aggregated human $\gamma$-globulin, suggesting impaired binding to Kupffer cells and defective phagocytosis (27), similar to that postulated in the present study.

The pathway of IC clearance in nonhuman primates has been established in baboons and chimpanzees $(4,6,28)$. Large immune complexes injected into the circulation bound efficiently to erythrocytes and were cleared in the liver. Blocking experiments using monoclonal anti-Fc $\gamma$ III in chimpanzees showed that these receptors were involved in hepatic clearance of soluble anti-dsDNA/dsDNA ICs (28). Maximal blockade of IC uptake by the liver was observed with IC fractions that did not bind to erythrocytes and had presumably bound less $C 3 b$. These data offer a hypothesis for the release of ICs from the liver, observed in the present studies. Kupffer cells bear the following Fc and complement receptors: Fc $\gamma$ I, II, and III, and 


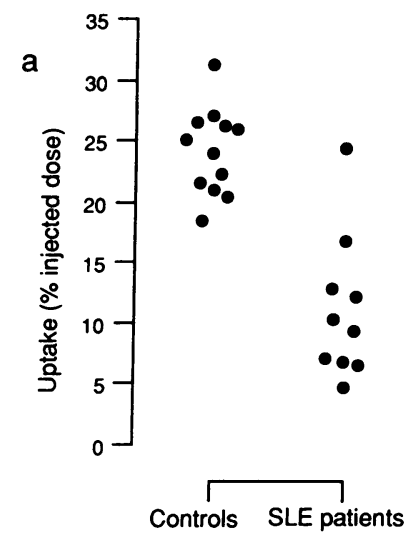

b

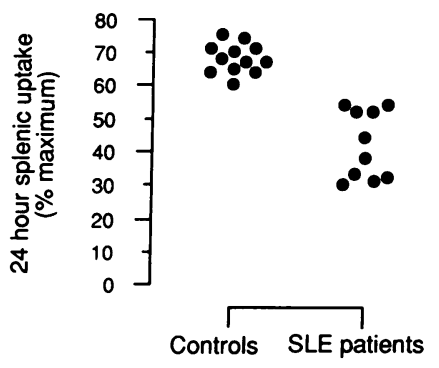

Figure 7. (a) Splenic IC uptake at $1 \mathrm{~h}$ (percent injected dose) in normals and patients. There was reduced uptake in the patient group. (b) Retention of IC in the spleen at $24 \mathrm{~h}$ in normals and patients. There was a reduced capacity of the spleen to retain IC in the SLE patients.

CR1, CR3, and CR4 (29-31). Myones et al. (32) demonstrated by radioligand binding assays using specific monoclonal antibodies that CR1 was expressed on monocyte-derived macrophages at $\sim 25 \%$ of the level of CR3 and $50 \%$ of the level of CR4 expression, but only showed weak staining of tissue macrophages by immunoperoxidase-labeled anti-CR 1 antibodies. More recently, immunohistochemical analysis of CR expression has been performed on normal human liver tissue obtained by percutaneous biopsy (33). Kupffer cells were identified using monoclonal antibody EBM11. These cells costained strongly in all cases with monoclonal antibodies to both CR1 and CR3 whereas weaker staining was demonstrated with anti-LeuM5 (anti-p150,95), suggesting a lower level of receptor expression. It may be that ligation of both Fc and CRs is required to mediate efficiently endocytosis and phagocytosis of ICs. In hypocomplementemic subjects, immune complexes bearing low numbers of $\mathrm{C} 3$ and $\mathrm{C} 4$ may bind transiently to Fc receptors on the Kupffer cell surface and then a proportion are released back into the circulation.

We previously studied the clearance mechanisms in humans of ${ }^{125} \mathrm{I}$-soluble tetanus toxoid (TT)/antitetanus toxoid complexes $(7,8)$ and found that complexes were cleared from the circulation more rapidly in patients with SLE and/or hypocomplementemia than in normal subjects. The site of clear-

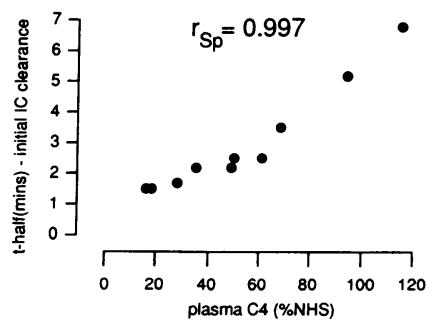

Figure 8. Correlation between plasma C4 and initial IC clearance rate in patients with SLE.
Table I. Comparison of Immune Complex Processing in Two SLE Patients Studied on Two Separate Occasions

\begin{tabular}{lcccccccc}
\hline Patient & DNA & C4 & \multicolumn{1}{c}{$\mathrm{T}_{1 / 2}$} & T90 & Max Sp. & Max Liv & E-CR1 & E-IC \\
\hline & $\%$ & $\%$ & \multicolumn{2}{c}{$\min$} & \multicolumn{2}{c}{ \% injected } & mol/cell & $\%$ bound \\
R.B. 1 & 66 & 18 & 1.33 & 6.0 & 12.27 & 46.45 & 490 & 26 \\
R.B. 2 & 33 & 28 & 1.90 & 9.0 & 16.1 & 41.05 & 504 & 28 \\
C.P. 1 & 64 & 15 & 1.30 & 9.0 & 21.6 & 58.02 & 570 & 32 \\
C.P. 2 & 20 & 40 & 2.3 & 12.5 & 28.0 & 53.10 & 582 & 34
\end{tabular}

DNA, percent DNA binding measured by Farr assay; $T_{1 / 2}$, half-time for initial IC clearance; T90, time for $90 \%$ hepatic IC uptake; Max $\mathrm{Sp} / \mathrm{Liv}$, maximum percent splenic and hepatic IC uptake; E-IC, maximum percent binding of IC to erythrocytes. $\mathrm{C} 4$ levels are measured by radial immunodiffusion assay, and reported as a percentage of values obtained using pooled normal human serum.

ance of these complexes was not ascertained and we interpreted the very fast clearance rate of complexes to be due to trapping of ICs outside the MPS, possibly in the pulmonary vasculature. This interpretation was probably incorrect in the light of the present data. Other studies have also shown IC clearance to be abnormally fast in patients with SLE, notably a recent study by Madi et al. (9), using similar $\mathrm{HBsAg} /$ anti-HBsAg complexes to those in the present study, in which the clearance sites of the immune complexes were not visualized.

Another model for the study of IC clearance is the use of aggregated IgG (A-IgG) $(6,10)$. Halma et al. (10) reported abnormally rapid initial A-IgG clearance by the liver in patients with SLE and decreased maximum splenic uptake, but there were no correlations observed between E-CR 1 and A-IgG binding to erythrocytes or between complement levels and elimination kinetics.

It is of some interest to contrast the present findings with the results of analyses of MPS function using IgG- or complement-coated erythrocytes as probes. Erythrocytes coated with anti-rhesus IgG, which did not fix complement, were mainly removed from the circulation in the spleen, clearance mediated by $\mathrm{Fc}$ receptors $(34,35)$. In contrast, erythrocytes coated with IgM and C3 are retained transiently in the liver by ligation of C3 receptors $(34,36,37)$. Catabolism of the C3 on the erythrocytes to C3dg was accompanied by their release back to the circulation. We do not have precise data on the ratio of immunoglobulin to $\mathrm{C} 3$ on our immune complexes, as these parameters changed quickly in vivo after IC injection (illustrated in Fig. $6 b$, which shows the changes in IC size after injection). However, up to $79 \%$ of the immune complexes bound to erythrocyte $C R 1$ in vivo, showing the presence of sufficient $C 3 b$ on the complexes to ligate these receptors efficiently. Furthermore, the median $t_{1 / 2}$ of IC binding to erythrocyte CR 1 was 7.8 min, longer than the median $t_{1 / 2}$ of complex clearance, showing that the IC still bore $\mathrm{C} 3 \mathrm{~b}$ or $\mathrm{iC} 3 \mathrm{~b}$ at the time of clearance.

Clearance of IgG-coated erythrocytes by the spleen was found to be delayed in patients with $\operatorname{SLE}(3,38)$ compared with normal subjects, and these data were interpreted to support the hypothesis that "reticulo-endothelial" blockade (2), possibly by high levels of endogenous immune complexes, may occur in patients with SLE. The present data and other studies on the clearance of soluble immune complexes do not support the hypothesis that there is blockade of the MPS in patients 
with SLE. It is possible that there is an isolated defect of splenic MPS function, but abnormal splenic blood flow has been demonstrated in patients with SLE and this may be a factor in determining the delayed uptake of IgG-coated erythrocytes (39).

The third major difference in immune complex processing between normal subjects and patients with SLE observed in this study related to the uptake of IC in the spleen. At $1 \mathrm{~h}$ after injection only $\sim 10 \%$ of injected IC were present in the spleen in the patients compared with one quarter in the normals, suggesting preferential uptake in the liver and reduced initial splenic localization. We also found that antigen was retained much more efficiently in the spleen in the normals than in the hypocomplementemic subjects: $15-20 \%$ injected activity was still measurable in the spleen at $24 \mathrm{~h}$ in normals compared with $3-5 \%$ in patients. The splenic clearance of IgG-coated erythrocytes has also been shown to be abnormal in patients with SLE, as discussed above, although early work suggested a correlation between $t_{1 / 2}$ of E-IgG clearance and disease activity $(3,38)$, later studies have failed to confirm these observations $(35,40)$. The uptake of radiolabeled A-IgG by the spleen has also been shown previously to be reduced in SLE patients (5). The anatomical organization of the spleen is ideally suited to the processing of erythrocytes, particulate antigens, and opsonized immune complexes delivered on erythrocytes bound to CR 1 . The splenic red pulp has a complex and highly specialized vasculature organized in a reticular mesh that functions as a filtration bed (41). Plasma and cells are progressively separated as blood passes through the organ, resulting in a relatively elevated hematocrit in the red pulp, an environment suited to the interaction of opsonized IC bound to red cell CRI and the periarterial macrophages. Hypocomplementemia, and reduced erythrocyte CR1 result in defective opsonization of IC and much reduced binding to erythrocytes. We hypothesize that it is abnormal delivery of IC to the mononuclear phagocytic system that results in reduced initial uptake and impaired complex retention in the spleen. A parallel may be drawn between these results and experiments demonstrating the importance of the complement system in determining the binding of immune complexes to follicular dendritic cells (42-44), a process important in the generation of memory $B$ lymphocytes. We speculate that hypocomplementemia and abnormal processing of immune complexes may be associated with abnormal pathways of antigen processing and presentation and that this may be a factor in promoting the autoimmune response in SLE.

In conclusion, we have presented evidence that the clearance pathway of large soluble immune complexes from the circulation in patients with SLE is abnormal and, in particular, that hepatic processing of immune complexes is impaired. There was reduced uptake of immune complexes in the spleen. These abnormalities may play a role in the immunopathogenesis of the disease by allowing immune complex deposition in tissues outside the MPS and, speculatively, by promoting abnormal pathways of antigen presentation.

\section{Acknowledgments}

We are grateful to Ms. B. Henderson in Nuclear Medicine at Hammersmith Hospital for her assistance with the scanning, and Dr. Jurg Schifferli and Professor P. J. Lavender for their helpful advice.

The work described in this study was funded by the Arthritis and Rheumatism Council of Great Britain.

\section{References}

1. Lachmann, P. J., and M. J. Walport. 1987. Deficiency of the effector mechanisms of the immune response and autoimmunity. In Autoimmunity and Autoimmune Disease, Ciba Foundation Symposium 129. J. Whelan, editor. Wiley Ltd., Chichester, England. 149-171.

2. Haakenstad, A. O., and M. Mannik. 1974. Saturation of the reticuloendothelial system with soluble immune complexes. J. Immunol. 112:1939-1947.

3. Hamburger, M. I., T. J. Lawley, R. P. Kimberly, P. H. Plotz, and M. M. Frank. 1982. A serial study of splenic reticuloendothelial system Fc-receptor function in systemic lupus erythematosus. Arthritis Rheum. 25:48.

4. Cornacoff, J. B., L. A. Hebert, W. L. Smead, M. E. VanAman, D. J. Birmingham, and F. J. Waxman. 1983. Primate erythrocyte-immune complexclearing mechanism. J. Clin. Invest. 71:236-247.

5. Lobatto, S., M. R. Daha, F. C. Breedveld, E. K. Pauwels, J. H. Evers Schouten, A. A. Voetman, A. Cats, and L. A. van Es. 1988. Abnormal clearance of soluble aggregates of human immunoglobulin $\mathrm{G}$ in patients with systemic lupus erythematosus. Clin. Exp. Immunol. 72:55-59.

6. Lobatto, S., M. R. Daha, A. A. Voetman, J. H. Evers-Schouten, A. A. Van Es, E. K. J. Pauwels, and L. A. van Es. 1987. Clearance of soluble aggregates of immunoglobulin $\mathrm{G}$ in healthy volunteers and chimpanzees. Clin. Exp. Immunol. 68:133-141.

7. Schifferli, J. A., Y. C. Ng, J. P. Paccaud, and M. J. Walport. 1989. The role of hypocomplementemia and low erythrocyte complement receptor type I numbers in determining abnormal immune complex clearance in humans. Clin. Exp. Immunol. 75:329-335.

8. Schifferli, J. A., Y. C. Ng, J. Estreicher, and M. J. Walport. 1988. The clearance of tetanus toxoid/anti-tetanus toxoid immune complexes from the circulation of humans. J. Immunol. 140:899-908.

9. Madi, N., G. Steiger, J. Estreicher, and J. A. Schifferli. 1991. Immune adherence and clearance of hepatitis $\mathrm{B}$ surface $\mathrm{Ag} / \mathrm{Ab}$ complexes is abnormal in patients with systemic lupus erythematosus. Clin. Exp. Immunol. 85:373-378.

10. Halma, C., F. C. Breedveld, M. R. Daha, D. Blok, J. H. Evers-Schouten, J. Hermans, E. K. J. Pauwels, and L. A. van Es. 1991. Elimination of soluble 123I-labeled aggregates of IgG in patients with systemic lupus erythematosus. Arthritis Rheum. 34:442-452.

11. Madi, N., J.-P. Paccaud, G. Steiger, and J. A. Schifferli. 1989. Immune adherence of nascent hepatitis B surface antigen-antibody complexes in vivo in humans. Clin. Exp. Immunol. 78:201-206.

12. Reay, P. 1982. Use of N-bromosuccinamide for the iodination of proteins for radioimmunoassay. Ann. Clin. Biochem. 19:129-133.

13. Johns, P., and D. R. Stanworth. 1975. A simple numerical method for the construction of isokinetic sucrose density gradients, and their application to the characterisation of immunoglobulin complexes. J. Immunol. Methods. 10:231239.

14. Weir, D. M. 1986. Handbook of Experimental Immunology. Blackwell Scientific Publications, Oxford, England.

15. Walport, M. J., G. D. Ross, C. Mackworth Young, J. V. Watson, N. Hogg, and P. J. Lachmann. 1985. Family studies of erythrocyte complement receptor type 1 levels: reduced levels in patients with SLE are acquired, not inherited. Clin. Exp. Immunol. 59:547-554.

16. Hogg, N., G. D. Ross, D. B. Jones, M. Slusarenko, M. J. Walport, and P. J. Lachmann. 1984. Identification of an anti-monocyte monoclonal antibody that is specific for membrane complement receptor type one (CR1). Eur. J. Immunol. 14:236-243.

17. Fraker, P. J., and J. C. Speck. 1978. Protein and cell membrane iodinations with a sparingly soluble chloroamide, 1,3,4,6,-tetrachloro-3a,6a-diphenylglycoluril. Biochem. Biophys. Res. Commun. 80:849-857.

18. Myers, M. J., J. P. Lavender, J. B. de Olivera, and A. Maseri. 1981. A simplified method of quantitating organ uptake using a gamma camera. $\mathrm{Br}$. $J$. Radiol. 54:1062-1067.

19. Davies, K. A., S. Stewart, V. Hird, G. Sivalopenko, A. E. Epenetos, and M. J. Walport. 1990. In vivo formation and clearance of immune complexes in humans. J. Immunol. 144:4613-4620.

20. Miller, G. W., and V. Nussenzweig. 1975. A new complement function: solubilization of antigen-antibody aggregates. Proc. Natl. Acad. Sci. USA. 72:418-423.

21. Schifferli, J. A., P. Woo, and D. K. Peters. 1982. Complement-mediated inhibition of immune precipitation. Role of the classical and alternative pathways. Clin. Exp. Immunol. 47:555-562.

22. Hong, K., Y. Takata, K. Sayama, H. Konozo, J. Takeda, Y. Nakata, T. Kinoshita, and K. Inoue. 1984. Inhibition of immune precipitation by complement. J. Immunol. 133:1464-1469.

23. Iida, K., R. Mornaghi, and V. Nussenzweig. 1982. Complement receptor (CR1) deficiency in erythrocytes from patients with systemic lupus erythematosus. J. Exp. Med. 155:1427-1438.

24. Minota, S., C. Terai, Y. Nojima, K. Takano, E. Takai, Y. Miyakawa, and F. Takaku. 1984. Low C3b receptor reactivity on erythrocytes from patients with 
systemic lupus erythematosus detected by immune adherence hemagglutination and radioimmunoassays with monoclonal antibody. Arthritis Rheum. 27:13291335

25. Holme, E., A. Fyfe, A. Zoma, J. Veitch, J. Hunter, and K. Whaley. 1986. Decreased C3b receptors (CR1) on erythrocytes from patients with systemic lupus erythematosus. Clin. Exp. Immunol. 63:41-48.

26. Finbloom, D. S., and P. H. Plotz. 1979. Studies of reticuloendothelial function in the mouse with model immune complexes. II. Serum clearance, tissue uptake, and reticuloendothelial saturation in NZB/W mice. J. Immunol. 123:1600-1603.

27. Magilavy, D. B., A. Rifai, and P. H. Plotz. 1981. An abnormality of immune complex kinetics in murine lupus. J. Immunol. 126:770-774.

28. Kimberly, R. P., J. C. Edberg, L. T. Merriam, S. B. Clarkson, J. C. Unkeless, and R. P. Taylor. 1989. In vivo handling of soluble complement fixing $\mathrm{Ab} / \mathrm{dsDNA}$ immune complexes in chimpanzees. J. Clin. Invest. 84:962-970.

29. Ross, G. D., and M. E. Medof. 1985 . Membrane complement receptors specific for bound fragments of C3. Adv. Immunol. 37:217-267.

30. Smedsred, B., H. Pertoft, G. Eggertsen, and C. Sundström. 1985. Functional and morphological characterization of cultures of Kupffer cells and liver endothelial cells prepared by means of density separation in Percoll, and selective substrate adherence. Cell Tissue Res. 241:639-649.

31. Unkeless, J. C. 1991. Function and heterogeneity of human Fc receptors for immunoglobulin G. J. Clin. Invest. 83:355-361.

32. Myones, B. L., J. G. Dalzell, N. Hogg, and G. D. Ross. 1988. Neutrophil and monocyte cell surface p150,95 has iC3b-receptor (CR4) activity resembling CR3. J. Clin. Invest. 82:640-651.

33. Hinglais, N., M. D. Kazatchkine, C. Mandet, M. D. Appay, and J. Bariety. 1989. Human liver Kupffer cells express CR1, CR3, and CR4 complement receptor antigens. An immunohistochemical study. Lab. Invest. 61:509-514.

34. Frank, M. M., T. J. Lawley, M. I. Hamburger, and E. J. Brown. 1983. Immunoglobulin G Fc receptor-mediated clearance in autoimmune diseases. Ann. Intern. Med. 98:206-218.
35. Kimberly, R. P., and P. Ralph. 1983. Endocytosis by the mononuclear phagocyte system and autoimmune disease. Am. J. Med. 74:481-493.

36. Brown, D. L., P. J. Lachmann, and J. V. Dacie. 1970. The in vivo behavior of complement-coated red cells: studies in C6-deficient, C3-depleted, and norma rabbits. Clin. Exp. Immunol. 7:401-422.

37. Atkinson, J. P., and M. M. Frank. 1974. Studies on the in vivo effects of antibody. Interaction of IgM antibody and complement in the immune clearance and destruction of erythrocytes in man. J. Clin. Invest. 54:339-348.

38. Frank, M. M., M. I. Hamburger, T. J. Lawley, R. P. Kimberly, and P. H. Plotz. 1979. Defective reticuloendothelial system Fc-receptor function in systemic lupus erythematosus. N. Engl. J. Med. 300:518-523.

39. Walport, M. J., A. M. Peters, K. B. Elkon, C. Pusey, J. P. Lavender, and G. R. V. Hughes. 1985. The splenic extraction ratio of antibody-coated erythrocytes and its response to plasma exchange and pulse methylprednisolone. Clin. Exp. Immunol. 60:465-473.

40. Van Der Woude, F. J., M. Van Der Giessen, C. G. M. Kallenberg, W. Ouwehand, H. Beekhuis, J. M. Beelen, W. J. Van Son, P. H. J. Hoedemaker, G. K. Van Der Hem, and T. H. The. 1984. Reticuloendothelial Fc receptor function in SLE patients. I. Primary HLA linked defect or acquired dysfunction secondary to disease activity? Clin. Exp. Immunol. 55:473-480.

41. Weiss, L. 1988. The Spleen, Cell and Tissue Biology. L. Weiss, editor. Urban and Schwarzenberg, Baltimore, MD. 517 pp.

42. Pepys, M. B. 1974. Role of complement in induction of antibody production in vivo. Effect of cobra venom factor and other C3-reactive agents on thymus-dependent and thymus-independent antibody responses. J. Exp. Med. 140:126-145.

43. Pryjma, J., and J. H. Humphrey. 1975. Prolonged C3 depletion by cobra venom factor in thymus-deprived mice and its implication for the role of $\mathrm{C} 3$ as an essential second signal for B-cell triggering. Immunology. 28:569-576.

44. Klaus, G. G. B., and J. H. Humphrey. 1977. The generation of memory cells. I. The role of $\mathrm{C} 3$ in the generation of B memory cells. Immunology. 33:3140. 